\title{
Influence of Intensive Melt Shearing on the Microstructure and Mechanical Properties of an Al-Mg Alloy with High Added Impurity Content
}

\author{
S. KUMAR, N. HARI BABU, G.M. SCAMANS, and Z. FAN
}

\begin{abstract}
We have investigated the influence of melt conditioning by intensive shearing on the mechanical behavior and microstructure of $\mathrm{Al}-\mathrm{Mg}-\mathrm{Mn}-\mathrm{Fe}-\mathrm{Cu}-\mathrm{Si}$ alloy sheet produced from a small book mold ingot with high added impurity content. The melt conditioned ingot has fine grains throughout its cross section, whereas a conventionally cast ingot, without melt shearing, has coarser grains and shows a wider variation of grain size. Both needle-shaped and coarse Chinese script iron bearing intermetallic particles are found in the microstructure at the center of the conventionally processed ingot, but for the melt conditioned ingot, only fine Chinese script intermetallic particles are observed. In addition to the iron bearing intermetallics, $\mathrm{Mg}_{2} \mathrm{Si}$ particles are also observed. The ingots were rolled to thin sheet and solution heat treated (SHT). During rolling, the iron-based intermetallics and $\mathrm{Mg}_{2} \mathrm{Si}$ particles are broken and aligned along the rolling direction. Yield strength (YS), ultimate tensile strength (UTS), and elongation of the intensively melt sheared and processed sheet are all improved compared to the conventionally cast and processed sheet. Fractographic analysis of the tensile fracture surfaces shows that the clustered and coarse iron bearing intermetallic particles are responsible for the observed reduction in mechanical properties of the conventionally cast sheet. We have shown that by refining the initial microstructure of the ingot by intensive shear melt conditioning, it is possible to achieve improved mechanical properties at the final sheet gage of an AlMgMn alloy with a high content of impurities.
\end{abstract}

DOI: $10.1007 / \mathrm{s} 11661-011-0722-\mathrm{Z}$

(C) The Minerals, Metals \& Materials Society and ASM International 2011

\section{INTRODUCTION}

THE AA5xxx (Al-Mg) series aluminum alloys were used extensively for applications in automotive structures ${ }^{[1-5]}$ due to their high work hardening rate and good formability. ${ }^{[6]}$ These alloys are presently made from primary aluminum and recovered process scrap. In the longer term, the increased use of postconsumer recycled scrap $^{[8-10]}$ in alloy formulation will inevitably result in higher levels of contamination by impurities such as copper, iron, and silicon, which could have an adverse effect on formability and other properties. These impurities react with other alloying elements, especially magnesium and manganese, to form intermetallic particles (e.g., $\mathrm{Al}_{6}(\mathrm{FeMn}), \mathrm{Al}_{m}(\mathrm{FeMn}), \mathrm{Al}_{3}(\mathrm{FeMn})$, $\mathrm{MgCuAl}_{2}$, and $\mathrm{Mg}_{2} \mathrm{Si}$ ) during ingot solidification, ${ }^{[11-15]}$ and the type, size, and distribution of these secondphase particles depend on the local solidification conditions. ${ }^{[15-17]}$ These phases affect the rolling process and influence the final sheet properties. ${ }^{[6,7,18]}$

The melt conditioning by advanced shearing technology (MCAST) process can be used to treat melts of aluminum and magnesium alloys under both semi-

S. KUMAR, Research Fellow, N. HARI BABU, Lecturer, and G.M. SCAMANS and Z. FAN, Professors, are with the EPSRC Centre-LiME, BCAST, Brunel University, Uxbridge, Middlesex, UB8 3PH, United Kingdom. Contact e-mail: sd_kumar1@yahoo.com Manuscript submitted October 15, 2010.

Article published online May 19, 2011 solid $^{[19,20]}$ and fully liquid conditions ${ }^{[21-25]}$ and can produce refined cast microstructures with significantly reduced segregation. In the present study, we examined the use of high shear melt conditioning on the tolerance of an AA5754 automotive sheet alloy to the addition of 0.6 wt pet $\mathrm{Fe}, 0.8$ wt pet $\mathrm{Si}$, and 0.5 wt pet $\mathrm{Cu}$. These levels were based on formulation of the AA5754 alloy from a high level of recycled old rolled aluminum sheet as the postconsumer scrap source.

\section{EXPERIMENTAL DETAILS}

The composition of the primary metal AA5754 alloy used as the base alloy in this study is given in Table I. The alloy was melted in a clay graphite crucible at a temperature of $1028 \mathrm{~K}\left(755^{\circ} \mathrm{C}\right)$, and controlled additions of 0.6 wt pet $\mathrm{Fe}, 0.8$ wt pet $\mathrm{Si}$, and 0.5 wt pet $\mathrm{Cu}$ were made to the melt as Al-46 wt pct Fe, Al-50 wt pct Si master alloys and as pure copper. The composition of the modified alloy is also shown in Table I. An addition of $0.1 \mathrm{wt}$ pet of Al-5Ti-1B grain refiner was made to the liquid metal 10 minutes before casting. Ingots were then cast with and without high shear melt conditioning. For the conventional casting process, the liquid metal was poured at $993 \mathrm{~K}\left(720{ }^{\circ} \mathrm{C}\right)$ into a preheated $(623 \mathrm{~K}$ $\left(350{ }^{\circ} \mathrm{C}\right)$ ) cast-iron book mold $190 \times 166 \times 34 \mathrm{~mm}$ in size. For casting after intensive shearing, the liquid metal at $953 \mathrm{~K}\left(680{ }^{\circ} \mathrm{C}\right)$ was poured into the melt 
conditioning unit and the melt was then intensively sheared by twin screws rotating at $500 \mathrm{rpm}$ for $60 \mathrm{sec}-$ onds at $923 \mathrm{~K}\left(650^{\circ} \mathrm{C}\right)$. The sheared melt was then cast into the preheated book mold. It is important to note that intensive shearing was done in the liquid state of the modified alloy, whose liquidus temperature was $908 \mathrm{~K}$ $\left(635^{\circ} \mathrm{C}\right)$. The details of the MCAST processing unit were published. ${ }^{[26,27]}$ The ingots were scalped $(2 \mathrm{~mm}$ on each side) and homogenized at $833 \mathrm{~K}\left(560{ }^{\circ} \mathrm{C}\right)$ for 2 hours. After homogenization, the ingots were hot rolled to $10 \mathrm{~mm}$ and then cold rolled to $1-\mathrm{mm}$-thick sheet. Samples cut from the rolled sheet were then solution heat treated (SHT) at $803 \mathrm{~K}\left(530{ }^{\circ} \mathrm{C}\right)$ for 60 seconds in a salt bath and water quenched. Figure 1 shows the processing sequences.

Tensile properties were measured in the longitudinal, transverse directions and at a $45 \mathrm{deg}$ angle to the rolling direction of the sheet. Longitudinal tensile tests were carried out on 220-mm-long, full-sized specimens with an extensometer on the $50-\mathrm{mm}$ gage length, whereas the transverse and $45 \mathrm{deg}$ angle tests were carried on $100-\mathrm{mm}$ subsized specimens with an extensometer on the 25-mm gage length according to the ASTM E8M-08

Table I. Chemical Composition of the Al-Mg Alloys in Weight Percent

\begin{tabular}{lcccccccc}
\hline Alloy & $\mathrm{Mg}$ & $\mathrm{Si}$ & $\mathrm{Fe}$ & $\mathrm{Mn}$ & $\mathrm{Cu}$ & $\mathrm{Ti}$ & $\mathrm{B}$ & $\mathrm{Al}$ \\
\hline Primary & 3.12 & 0.05 & 0.20 & 0.43 & 0.001 & 0.02 & 0.006 & bal \\
Modified & 2.98 & 0.72 & 0.58 & 0.41 & 0.40 & 0.02 & 0.006 & bal \\
\hline
\end{tabular}

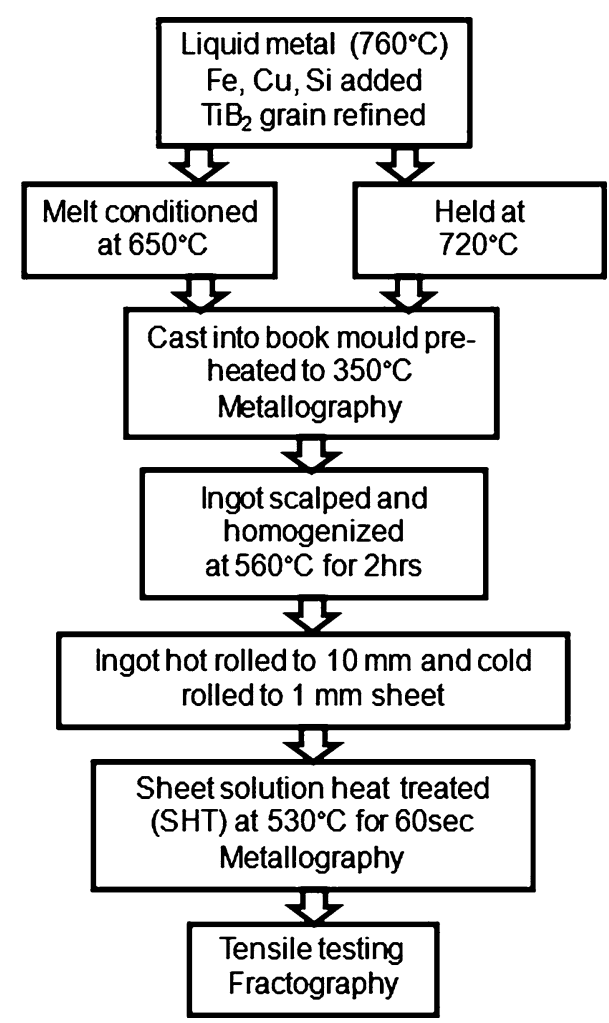

Fig. $1-$ Schematic of the casting, processing, and testing route for the AA5754 alloys. standard. The tensile tests were carried out at Westmoreland Mechanical Testing and Research Ltd. (Banbury, United Kingdom). The through thickness microstructure of the as-cast rolling blocks was sectioned for metallographic examination, and the microstructure of the heat-treated rolled sheet was also examined using transverse, longitudinal, and surface

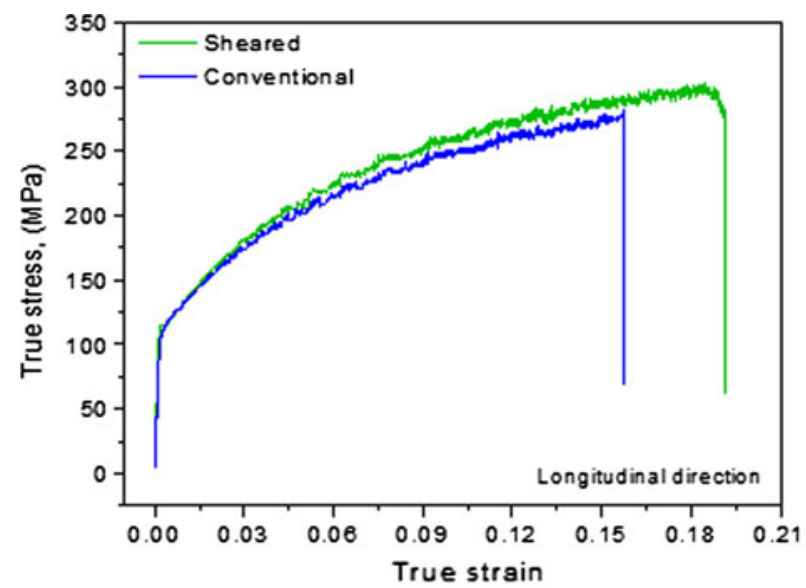

(a)

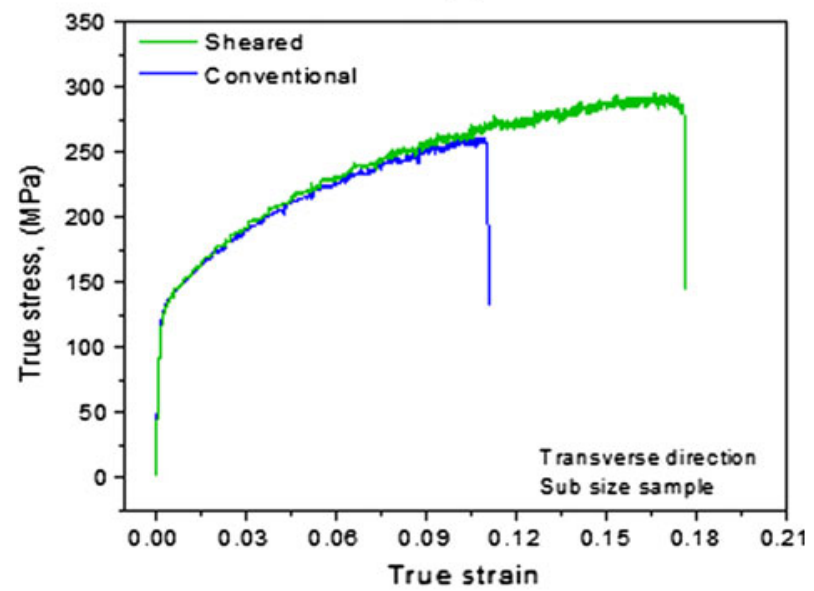

(b)

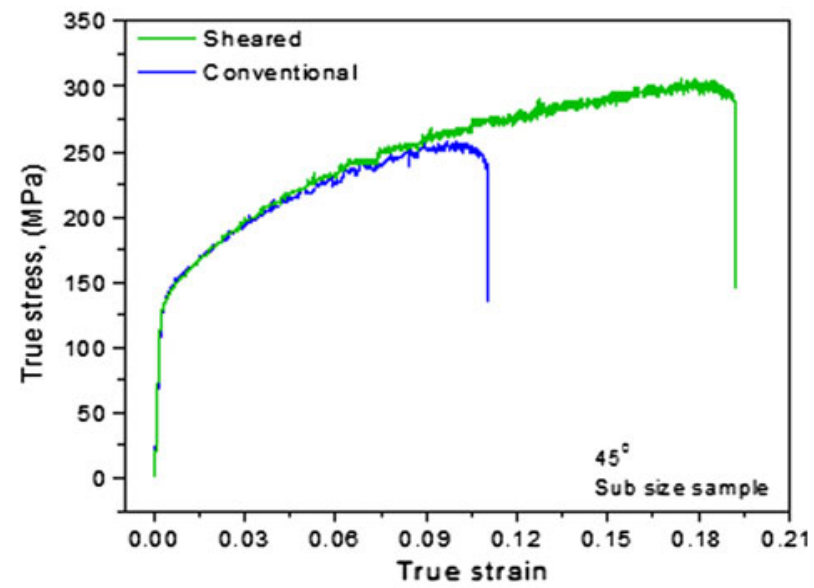

(c)

Fig. 2-True SS curves for the sheet from both the conventionally cast and the melt conditioned ingots tested parallel, perpendicular, and at a $45 \mathrm{deg}$ angle to the rolling direction. 
sections. Samples for metallography were mounted, ground, and mechanically polished with a colloidal silica suspension having a grain size of $0.04 \mu \mathrm{m}$. As-polished samples were used to examine the morphology and distribution of the intermetallic phases. Polished samples were anodized at $20 \mathrm{~V}$ for 60 seconds in Barker's reagent ( $7 \mathrm{~mL} \mathrm{HBF}_{4}$ (48 pct), $93 \mathrm{~mL} \mathrm{H}_{2} \mathrm{O}$ ) to show the grain structure. The linear intercept method was used to measure the grain size on polarized images taken with a Zeiss Axioskop 2 MAT optical microscope (Carl Zeiss, Hertford Shire, UK). A Zeiss EVO 50 scanning electron microscope (SEM, Carl Zeiss NTS $\mathrm{GmbH}$, Oberkochen, Germany) equipped with a Princeton Gamma Tech energy-dispersive spectrometer (EDS, Princeton Gamma-Tech (PGT), Princeton, NJ, USA) was used to image microstructures and to qualitatively analyze particle compositions. Spatial variation of particle size $\left(D_{\text {circle }}\right)$ on the as-cast and rolled sheet was measured by image analysis of backscattered electron (BSE) images. The tensile fracture surfaces were also examined using an SEM.

\section{RESULTS}

\section{A. Tensile Properties}

Figure 2 shows the true stress strain (SS) curves of tensile samples machined from the rolled sheets tested along the longitudinal (Figure 2(a)), transverse (Figure 2(b)), and $45 \mathrm{deg}$ angle (Figure 2(c)) to the rolling direction. The average tensile properties for all three directions are given in Table II. Three samples were tested for each condition. The sheet from the shear processed ingot has an average yield strength (YS) of $131 \mathrm{MPa}$, ultimate tensile strength (UTS) of $253 \mathrm{MPa}$, and elongation of $19 \mathrm{pct}$, whereas the conventionally melted and processed sheet has an average YS of $127 \mathrm{MPa}$, UTS of $238 \mathrm{MPa}$, and elongation of 13 pet. The intensive shear process improves the elongation and strength of the high-impurity alloy. The base AA5754 alloy without the added impurities provided tensile property values of $116 \pm 5 \mathrm{MPa}$ average yield stress, 237 $\pm 2 \mathrm{MPa}$ average UTS, and an average elongation of 24 \pm 1 pct. This alloy had a grain size of $16 \pm 1 \mu \mathrm{m}$. Figure 3 shows that there was no significant difference in the grain size of conventional sheet $(23 \pm 5 \mu \mathrm{m})$ and the grain size of the sheet from the melt conditioned ingot $(17 \pm 3 \mu \mathrm{m})$. The increased yield stress of the impurity containing alloys, with or without melt conditioning, compared to the base alloy is probably due to the increased level of copper. As the high-impurity alloys have a similar grain size, the improved elongations of the sheet from the melt conditioned ingot are not due to grain size effects.

\section{B. Fractography of Tensile Samples}

Figure 4 shows images from the fracture surfaces of tensile samples tested in the longitudinal orientation. The fracture faces show typical ductile, cup, and cone fractures with populations of both fine and large dimples (Figures 4(a) and (b)). The main difference is that the conventionally cast and processed sheet fracture surface shows a higher number of the larger dimples

Table II. Average Mechanical Properties of Tensile Samples from Three Different Orientations (Longitudinal, Transverse, and 45 Deg); for Comparative Purposes, Primary Alloy (AA5754) Properties Are Also Given; the Error Bar Shows the Standard Deviation

\begin{tabular}{|c|c|c|c|c|c|c|c|c|c|c|}
\hline \multirow[b]{2}{*}{ Alloy } & \multirow[b]{2}{*}{ Process } & \multicolumn{3}{|c|}{ Longitudinal } & \multicolumn{3}{|c|}{ Transverse } & \multicolumn{3}{|c|}{45 Deg } \\
\hline & & $\begin{array}{c}0.2 \text { Proof } \\
\text { Strength } \\
(\mathrm{MPa})\end{array}$ & $\begin{array}{l}\text { UTS } \\
\text { (MPa) }\end{array}$ & $\begin{array}{l}\text { Elongation } \\
\text { (Pct) }\end{array}$ & $\begin{array}{c}0.2 \text { Proof } \\
\text { Strength } \\
(\mathrm{MPa})\end{array}$ & $\begin{array}{l}\text { UTS } \\
\text { (MPa) }\end{array}$ & $\begin{array}{l}\text { Elongation } \\
\text { (Pct) }\end{array}$ & $\begin{array}{c}0.2 \text { Proof } \\
\text { Strength } \\
(\mathrm{MPa})\end{array}$ & $\begin{array}{c}\text { UTS } \\
\text { (MPa) }\end{array}$ & $\begin{array}{l}\text { Elongation } \\
\quad \text { (Pct) }\end{array}$ \\
\hline Modified & conventional & $116 \pm 2$ & $242 \pm 3$ & $15 \pm 1$ & $130 \pm 4$ & $234 \pm 1$ & $11 \pm 1$ & $135 \pm 7$ & $239 \pm 4$ & $13 \pm 2$ \\
\hline Modified & intensively sheared & $119 \pm 3$ & $252 \pm 1$ & $18 \pm 2$ & $136 \pm 4$ & $252 \pm 1$ & $19 \pm 0.4$ & $137 \pm 4$ & $255 \pm 3$ & $19 \pm 3$ \\
\hline Primary & conventional & $107 \pm 2$ & $234 \pm 0.5$ & $24 \pm 1$ & $120 \pm 4$ & $240 \pm 1$ & 23 & $122 \pm 5$ & $238 \pm 1$ & $25 \pm 1$ \\
\hline
\end{tabular}
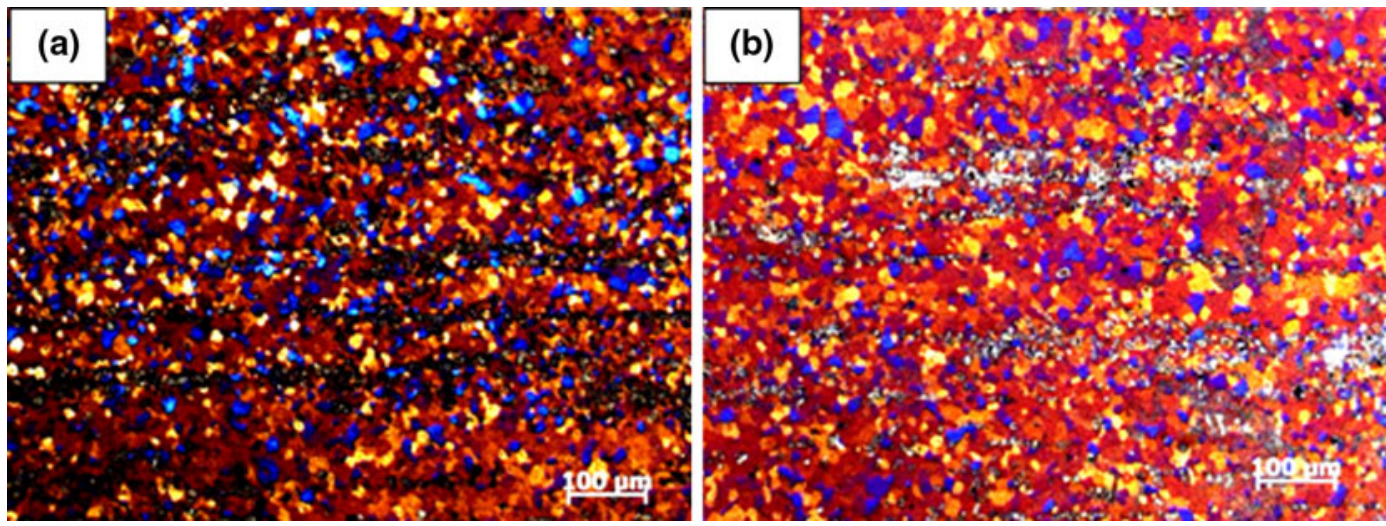

Fig. 3 - Grain structure of the sheet (a) conventionally cast and (b) melt conditioned and cast. 

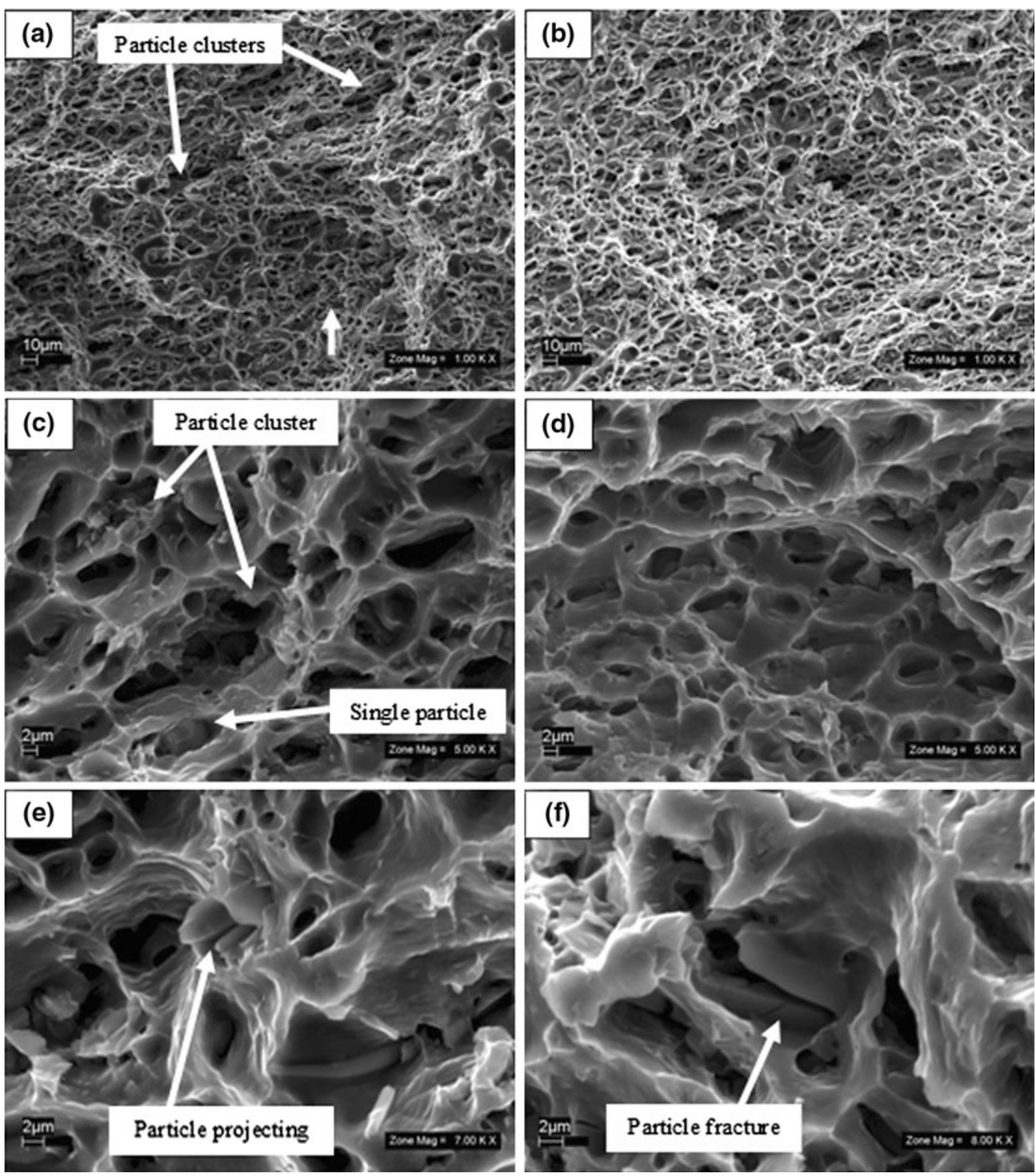

Fig. 4-SEM secondary electron images of the tensile fracture surfaces of $(a),(c),(e)$, and $(f)$ the conventionally cast sheet and $(b)$ and $(d)$ the melt conditioned cast sheet. Each dimple has iron inclusions at its center. For the conventionally cast sheet, large numbers of cluster nucleated dimples are observed (examples of cluster nucleated dimples are arrowed in (a) and (c)). The sheet from the melt conditioned ingot shows very few clusters and fewer large dimples, as shown in (d). (e) and (f) are images of intermetallic particles projecting from the fracture surface and of a fractured intermetallic particle.

(Figure 4(a)), compared to the sheet from the melt conditioned ingot (Figure 4(b)). The larger dimples are developed from fracture initiated at clusters of intermetallic particles (Figure 4(c)). In contrast, the smaller dimples have developed from single or much smaller clusters of intermetallic particles (Figure 4(d)). Intermetallic particles are also found projecting from fracture surfaces, and they show evidence of local fracture (Figures 4(e) and (f)).

\section{Rolled Sheet Microstructure}

Figure 5 shows comparative BSE images of both types of sheet from surface. During rolling, the intermetallic phases from the as-cast ingot are broken and aligned along the rolling direction (Figures 5(a) and (b)). This occurs for both the iron-based intermetallics and the $\mathrm{Mg}_{2} \mathrm{Si}$ particles. The comparative higher magnification images from the surface sections (Figures 5(c) and (d)) show that the particle clusters are agglomerates of fine fractured particles. EDS analysis of the bright particles (Figure 5(e)) showed that they contained Al, $\mathrm{Fe}, \mathrm{Mn}$, and $\mathrm{Si}$, whereas the dark contrast particles contained only magnesium and silicon (Figure 5(f)). Figure 6 shows the comparative size distribution of the iron bearing intermetallics and $\mathrm{Mg}_{2} \mathrm{Si}$ particles measured on the surface of the sheet. The size distribution was measured using BSE images taken at 10 different 

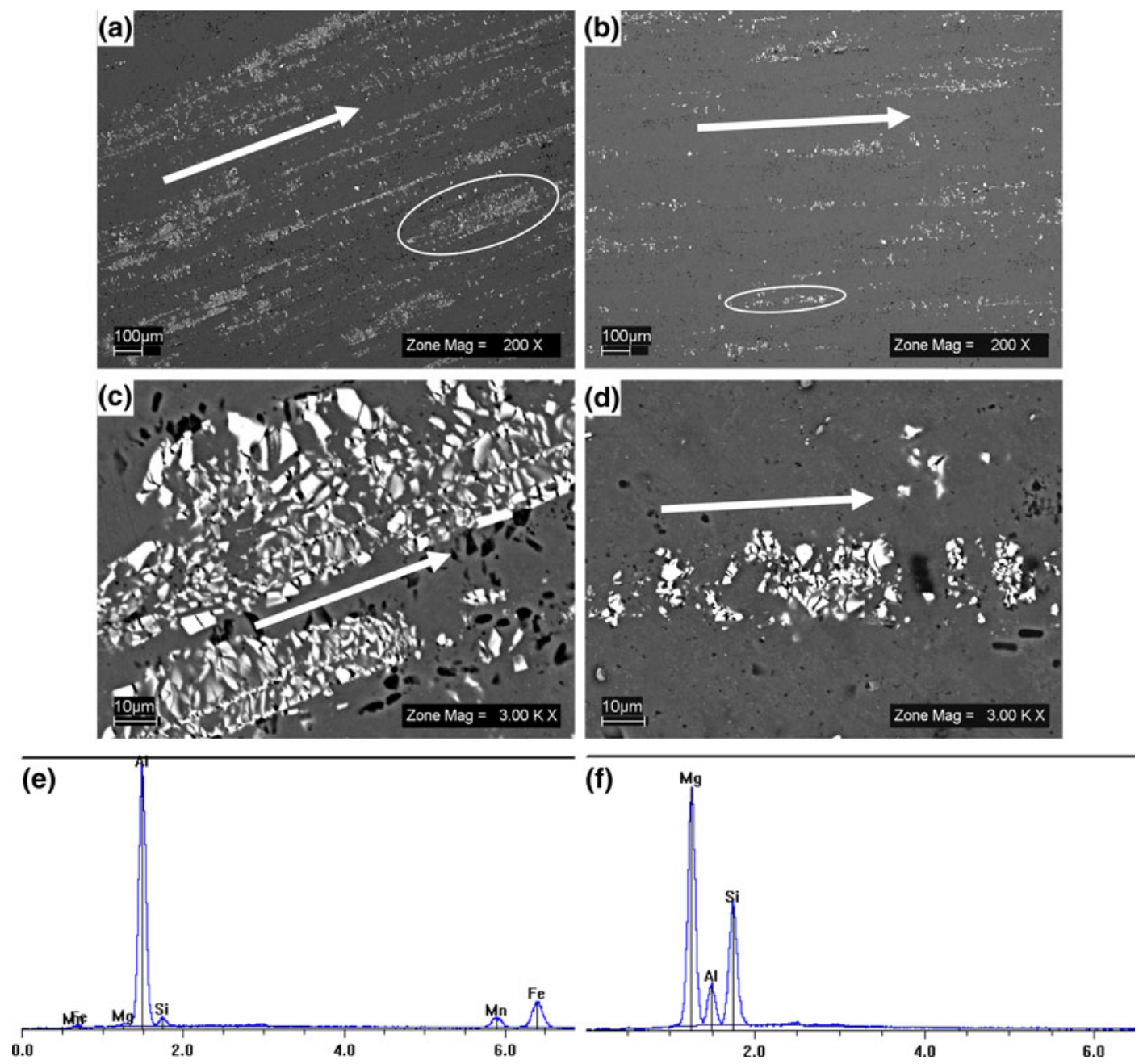

Fig. 5- $(a),(b),(c)$, and (d) BSE images from surface sections of the processed sheet with the arrow showing the rolling direction. The sheet from the melt conditioned ingot has smaller intermetallic clusters ((b) and (d)) than the sheet from the conventionally cast ingot ((a) and (c)). Typical cluster sizes are marked in (a) and (b), which show that the clusters are aligned in the rolling direction. The high-magnification images ((c) and (d)) show that the clusters on the surface of the rolled sheet consist of fractured as-cast intermetallics. The EDS analysis of the $(e)$ bright particles shows that they are Fe bearing intermetallics and that the $(f)$ dark particles are $\mathrm{Mg}_{2} \mathrm{Si}$.

locations on the surface. Both the iron bearing intermetallics (Figure 6(a)) and the $\mathrm{Mg}_{2} \mathrm{Si}$ (Figure 6(b)) particles are finer in the sheet processed from the melt conditioned ingot.

\section{As-Cast Microstructure}

Figure 7 shows the as-cast microstructures. The ingot cast from the sheared melt has a finer grain size. Figure 7(c) shows the grain size distribution along the cross section from the surface (A) to center (B) of the ingot. For the conventionally cast ingot, the mean grain size near the surface is $159 \pm 19 \mu \mathrm{m}$ and increases to 205 $\pm 21 \mu \mathrm{m}$ at the center, whereas for the intensively sheared ingot, the grain size near the surface is $144 \pm 13$ $\mu \mathrm{m}$ and increases to $173 \pm 8 \mu \mathrm{m}$ at the center. The position and orientation of the section taken from the cast ingot is shown by the inset in Figure 7(c).

The BSE images in Figure 8 show the iron bearing intermetallics and $\mathrm{Mg}_{2} \mathrm{Si}$ particles at different positions along the cross section of the ingots. These constituent particles are formed from the interdendritic liquid and are coarser at the center of the ingot. Both needleshaped and Chinese script iron bearing intermetallic particles are found at the center of the conventionally processed ingot (Figure 8(c)), but for the melt conditioned, the Chinese script intermetallic particles are finer and there are no needle-shaped intermetallics (Figure 8(d)). At all positions, the intensive melt has produced an ingot that has fine and uniformly distributed constituent particles (Figures 8(b) and (d)) compared to the conventional ingot.

Elemental analysis of the needle and Chinese script iron bearing intermetallic phases are shown in Figures 9(a) and (b), and Table III shows the average composition of 20 iron bearing particles of each shape. Based on both the average composition and earlier work, ${ }^{[11,15,30,31]}$ the Chinese script intermetallics are $\mathrm{Al}_{12}(\mathrm{Fe}, \mathrm{Mn}, \mathrm{Cu})_{3} \mathrm{Si}$ and the needle/platelet particles are $\mathrm{Al}_{3}(\mathrm{Fe}, \mathrm{Mn})$. The measured aluminum content in both cases is higher than stoichiometry due to additional spurious counts from the aluminum alloy matrix. 


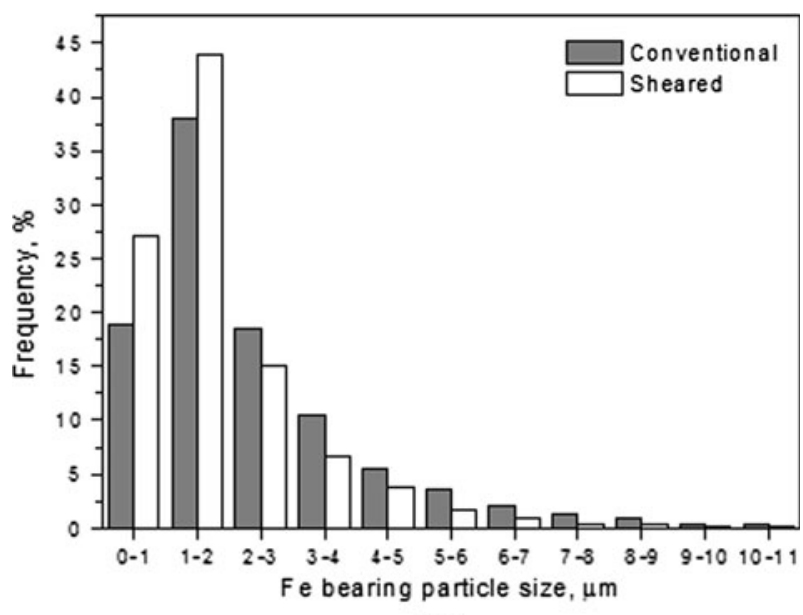

(a)

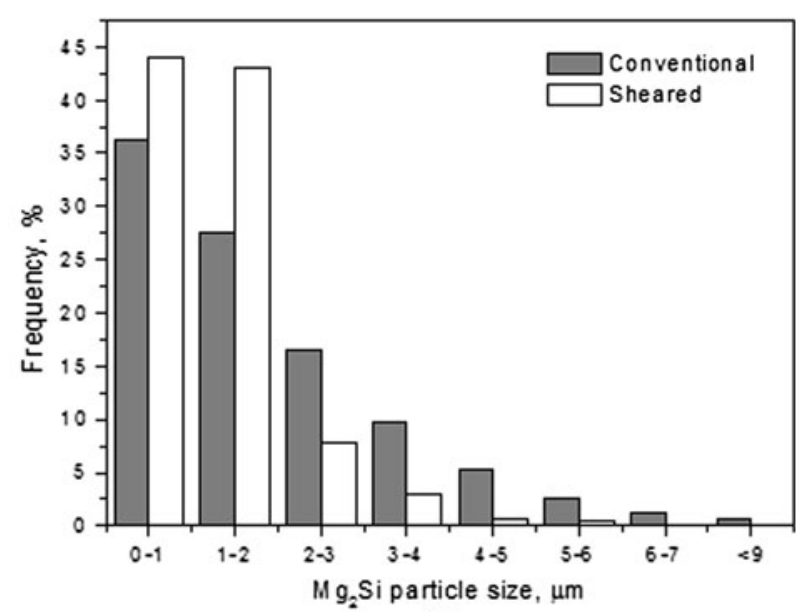

(b)

Fig. 6 - Size distributions of (a) Fe bearing and (b) $\mathrm{Mg}_{2} \mathrm{Si}$ constituent particles on the surface of the rolled sheet. The sheet from the melt conditioned ingot has finer Fe-rich and $\mathrm{Mg}_{2} \mathrm{Si}$ particles.

Figure 10 shows the size of the iron bearing particle (both types) across the ingots. It is clear that the equivalent diameter of the intermetallic phases in the conventionally cast ingot is higher than that of the ingot cast from an intensively sheared melt.

\section{DISCUSSION}

\section{A. Mechanical Behavior}

The ductility of the high-impurity content sheet from the melt conditioned ingot is better than that of the conventionally cast and processed sheet, irrespective of the tensile specimen orientation. The SS curves (Figure 2) show the typical serrated flow characteristic behavior of Al-Mg alloys. ${ }^{[28]}$ The maximum equilibrium solid solubility of silicon in aluminum is $1.7 \mathrm{wt}$ pct, and this decreases to $\sim 0.2 \mathrm{wt}$ pct when iron is present. ${ }^{[29]}$ Therefore, during nonequilibrium ingot solidification, most of the silicon segregates and forms second phases such as iron and silicon bearing intermetallic and $\mathrm{Mg}_{2} \mathrm{Si}$.
During thermomechanical processing and SHT, it is expected that low-temperature eutectic phases such as $\mathrm{MgCuAl}_{2}$ and $\mathrm{Mg}_{2} \mathrm{Si}$ dissolve into solid solution.

In the conventionally cast sheet, the clusters of intermetallic particles are of 50 to $100 \mu \mathrm{m}$ in width with the individual particles of $<10 \mu \mathrm{m}$ in size aligned along the rolling direction. These particle clusters act as a nucleation site for voids and cracks to form. Chen and Worswick $^{[30]}$ investigated void nucleation in $\mathrm{Al}-\mathrm{Mg}$ alloy sheet, and they observed that the area fraction of void nucleation increased with the second-phase particle concentration. They also noted that a lower strain is required to nucleate voids for alloys containing a large area fraction of second-phase particles. The variation in the elongation of the sheet with respect to the tensile direction can be attributed to the particle cluster alignment in the principle load direction (Figure 2). Thomas et al. ${ }^{[31]}$ demonstrated that the orientation of clustered particles with respect to the direction of applied stress plays a significant role in fracture. Basically, the clusters that are transverse to the tensile direction cause higher damage than clusters aligned to the tensile direction. Here, the clusters are aligned in the rolling direction, and therefore, the damage is most severe when the principal load is perpendicular to the rolling direction. The superior elongation of the high shear processed modified alloy may be due to the smaller clusters of iron bearing particles that are more uniformly distributed compared to the nonmelt conditioned highimpurity alloy.

\section{B. Microstructural Features}

\section{Grain size}

The grain size of the conventional cast ingot increases with distance from the mold surface and reaches a maximum at the center of the ingot. The cooling rate is not uniform and it decreases with an increase in the distance from the mold wall. During the solidification of the conventional ingot, fine grain forms near the mold wall and larger grains are formed at the center. When an alloy melt is subjected to intensive shearing, oxide films and oxide clusters are broken up and fine oxide particles are dispersed uniformly throughout the melt. Scamans and Fan $^{[32]}$ have shown that with intensive melt shearing of the aluminum casting alloy LM-24, oxide bi-films and oxide clusters $\left(\mathrm{MgAl}_{2} \mathrm{O}_{4}\right.$ and $\left.\mathrm{Al}_{2} \mathrm{O}_{3}\right)$ are dispersed into small crystallites of the size range of 200 to $300 \mathrm{~nm}$. These oxide particles act as potent nucleating sites. ${ }^{[24]}$ Two types of nucleation events were proposed during the solidification of intensive sheared liquid: ${ }^{[23]}$ (1) forced wetting of oxide particles, which then act as a potent nucleating substrate for the matrix; and (b) multistep nucleation mechanism, where oxide nucleates intermediate compounds, which then nucleate the $\alpha$-matrix. In addition, the intensive shearing provides the melt with uniform chemical composition. All this resulted in fine grains in the intensive sheared ingot.

\section{Fe bearing intermetallic phase}

The high levels of iron (0.6 wt pct) and silicon (0.8 wt pct) will result in the increased formation of eutectics of 

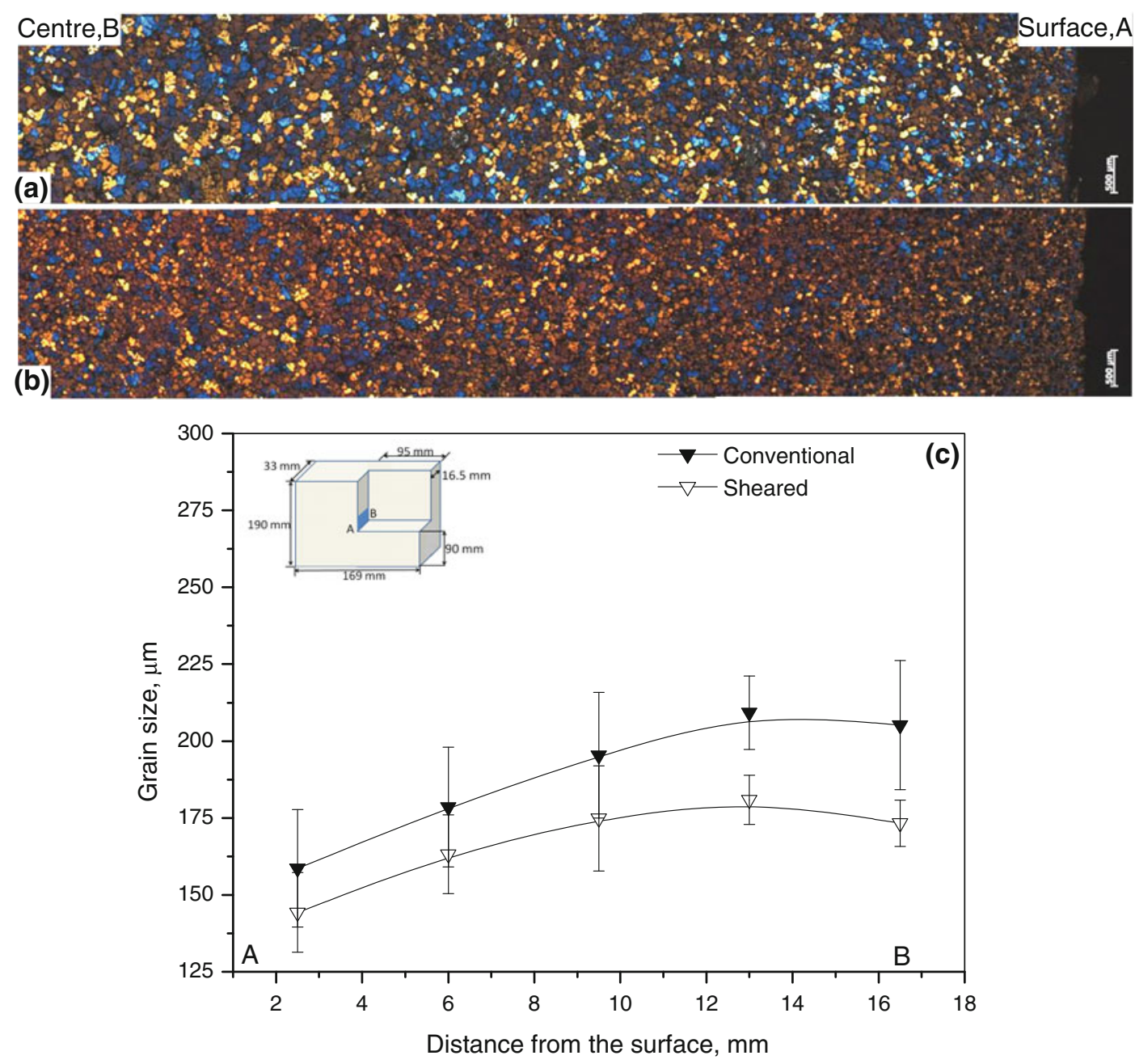

Fig. 7-Cross sections of the ingot (a) conventionally cast and (b) after melt conditioning and (c) the average grain size distribution from the surface (A) to the center (B) of ingots. A schematic illustration of where the section was made for the microstructural analyze is shown in (c).

$\alpha-\mathrm{Al}$ and iron and silicon phases between the dendrites. For book mold casting, the change in local cooling rate $(d T / d t)$ from the surface to the center causes the change of iron bearing intermetallic phase formation from the metastable to the stable phase. It also explains why the local eutectic chemical composition changes. The diffusion coefficient of iron and silicon in liquid aluminum is $8.43 \times 10^{-8}$ and $1.1 \times 10^{-5} \mathrm{~m}^{2} \mathrm{~s}^{-1}$, whereas the diffusion coefficient of iron and silicon in solid aluminum is $1.35 \times 10^{-2}$ and $2.02 \times 10^{-4} \mathrm{~m}^{2} \mathrm{~s}^{-1}$. ${ }^{[29]}$ Since silicon diffuses faster than iron in aluminum, the $\mathrm{Fe} / \mathrm{Si}$ ratio in the segregated eutectic liquid varies. ${ }^{[11]}$ Dutta and Rettenmayr ${ }^{[29]}$ predicted a drop in $\mathrm{Fe} / \mathrm{Si}$ ratio of the eutectic with increase in cooling rate. As a result, the type of metastable and stable intermetallic phases that form will depend on the local chemical composition and local cooling rate. The growth velocity of an $\alpha-\mathrm{Al}$ dendrite during the nonequilibrium solidification is directly proportional to its local cooling rate when the temperature gradient is constant and a high growth velocity favors metastable phase formation. ${ }^{[17]}$ Liang and Jones ${ }^{[33]}$ demonstrated the influence of growth velocity on the phase selection in Al-Fe binary alloys and showed that, for the same composition with high growth solidification velocity, $\mathrm{Al}_{6} \mathrm{Fe}$ eutectic was predominant, whereas $\mathrm{Al}_{3} \mathrm{Fe}$ eutectic was predominant at low growth velocity. This means that nonfaceted metastable phases such as $\alpha-\mathrm{Al}(\mathrm{FeMn})$ are formed near the surface, whereas faceted stable phases such as $\mathrm{Al}_{3}(\mathrm{FeMn})$ are formed at the center of the ingot (as in the conventional cast ingot (Figure 8)). Similar differences in the intermetallic phase distribution along the cross section of ingots were observed in other aluminum

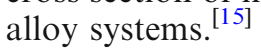

Unlike in conventionally cast ingot, intensive melt shearing and casting results in an ingot microstructure without $\mathrm{Al}_{3}(\mathrm{FeMn})$ needles or large $\alpha-\mathrm{Al}_{12}(\mathrm{Fe}, \mathrm{Mn}$, $\mathrm{Cu})_{3} \mathrm{Si}$ intermetallic phases and only uniformly distributed fine $\alpha-\mathrm{Al}_{12}(\mathrm{Fe}, \mathrm{Mn}, \mathrm{Cu})_{3} \mathrm{Si}$. Similar changes to the iron bearing intermetallic phases were also observed for Al-Si alloys after intensive shearing. ${ }^{[19]}$ The results demonstrate that intensive melt shearing directly influences the nucleation of iron-rich intermetallic phases. This refinement was attributed to the narrow size 

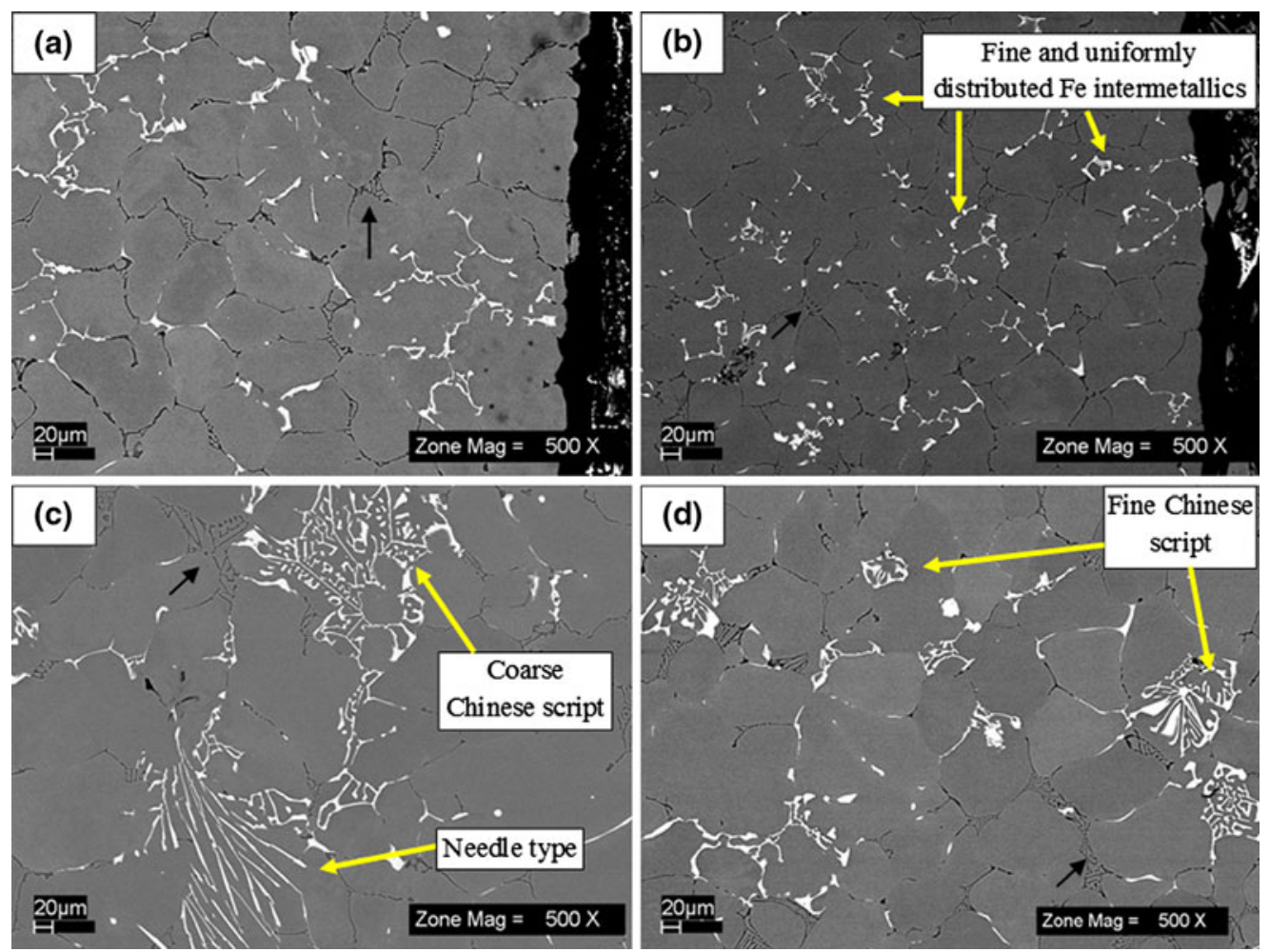

Fig. 8-BSE images from the $(a)$ and $(c)$ conventionally cast and $(b)$ and $(d)$ melt conditioned ingots. Images (a) and (b) are from near the mold wall and (c) and (d) are from the center of the ingot. The intensive shearing resulted in finer, more uniformly distributed constituent particles. The black arrows in (a) through (d) show the $\mathrm{Mg}_{2} \mathrm{Si}$.
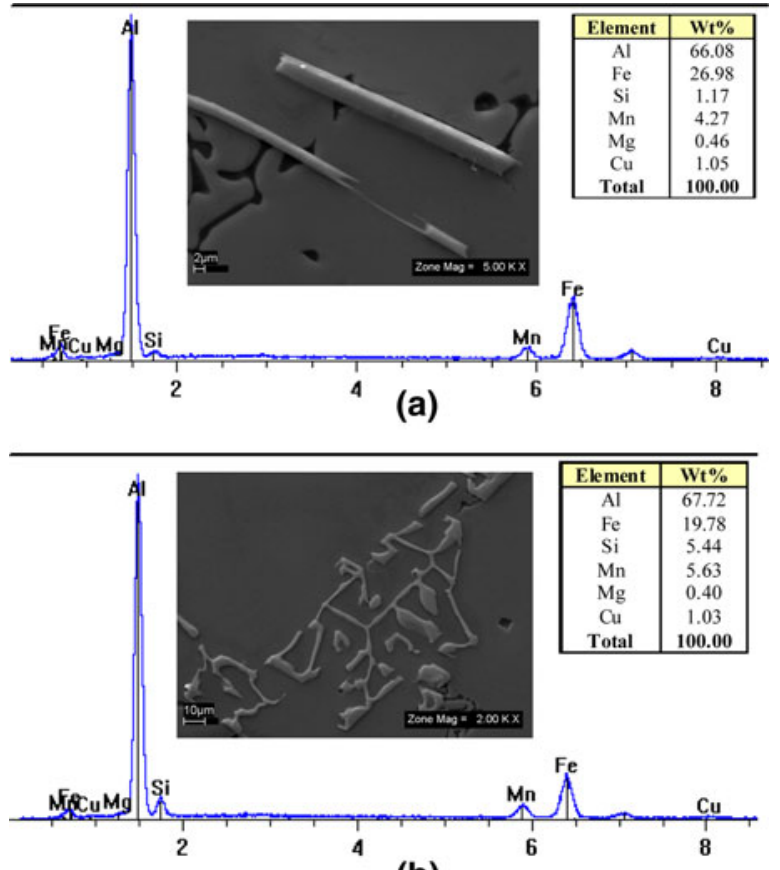

(b)

Fig. 9 -Energy-dispersive X-ray microanalysis of $(a)$ the needle morphology phase and $(b)$ the Chinese script morphology Fe bearing intermetallic particles. The needle-shaped particles have low $\mathrm{Si}$ and high Fe compared to the Chinese script type particle. Corresponding $\mathrm{SE}$ images and compositions are shown. The average composition measured from 20 different particles in each case is shown in Table III. distribution of oxide particles $\left(\mathrm{MgO}\right.$ and $\mathrm{MgAl}_{2} \mathrm{O}_{4}$ in Al-Mg alloys) after intensive shearing; the oxide particles act as heterogeneous nucleation sites for intermetallic particles. The effect of oxide inclusions on the nucleation of iron bearing intermetallic phases in aluminum alloys is well documented. ${ }^{[34-36]}$ Based on lattice matching, Cao and Campbell ${ }^{[34]}$ proposed that $\mathrm{MgO}, \mathrm{MgAl}_{2} \mathrm{O}_{4}, \alpha-\mathrm{Al}_{2} \mathrm{O}_{3}$, and $\gamma-\mathrm{Al}_{2} \mathrm{O}_{3}$ are all potent substrates for the nucleation of $\alpha \mathrm{Fe}$ intermetallic particles. The intermetallic nucleation mechanism can be either by direct nucleation on the dispersed oxides or by multistep nucleation, where an intermediate compound first forms on the oxide particles, which then nucleate the iron-based intermetallics. The finer $\alpha-\mathrm{Al}_{12}(\mathrm{Fe}, \mathrm{Mn}, \mathrm{Cu})_{3} \mathrm{Si}$ formation after intensive shearing could also be influenced by the refinement of the $\alpha$-Al.

The SHT sheets show clusters of intermetallic particles. During rolling, the as-cast particles are fractured and aligned along the rolling direction. The cluster size is directly related to the size of the as-cast particles. The smaller intermetallic clusters in the sheet produced from an intensively sheared melt are due to the finer size of the intermetallic particles in the as-cast ingot.

\section{CONCLUSIONS}

High shear melt conditioning of AA5754 alloy, with deliberate additions of iron, silicon, and copper, modifies the distribution of intermetallic particles in 
Table III. Chemical Composition (Weight Percent) of the Constituent Particles in the Conventionally Cast Ingot of the Modified Alloy; the Error Bar Shows the Standard Deviation

\begin{tabular}{lcccccc}
\hline Shape & $\mathrm{Al}$ & $\mathrm{Mg}$ & $\mathrm{Si}$ & $\mathrm{Fe}$ & $\mathrm{Mn}$ & $\mathrm{Cu}$ \\
\hline Chinese script & $68.72 \pm 1.63$ & $0.63 \pm 0.44$ & $5.26 \pm 0.59$ & $18.63 \pm 1.40$ & $6.06 \pm 1.47$ & $1.06 \pm 0.82$ \\
Needle & $66.79 \pm 1.21$ & $0.54 \pm 0.14$ & $1.02 \pm 0.15$ & $26.21 \pm 1.30$ & $4.87 \pm 0.79$ & $1.15 \pm 0.53$ \\
\hline
\end{tabular}

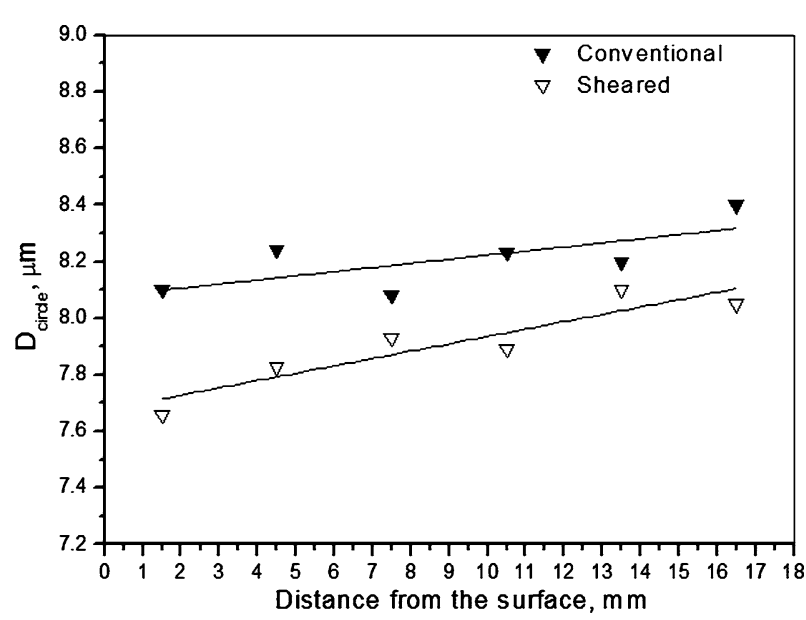

Fig. 10-Fe bearing particle size along the cross section of the cast ingots. The conventionally cast ingot shows a larger mean Fe bearing particle cluster size.

the as-cast ingot, and this results in improved fracture properties of sheet from the thermomechanically processed ingot. High shear melt conditioning can be used to increase the tolerance of $\mathrm{AlMgMn}$ alloys to impurities typical of those that increase from the use of post consumer scrap in melt formulation.

\section{ACKNOWLEDGMENTS}

The authors gratefully acknowledge the support of BCAST and the consortium under the Technology Strategy Board funded REALCAR project.

\section{REFERENCES}

1. G.B. Burger, A.K. Gupta, P.W. Jeffrey, and D.J. Lloyd: Mater. Charact., 1994, vol. 35, pp. 23-39.

2. W.S. Miller, L. Zhuang, J. Bottema, A.J. Wittebrood, P. De Smet, A. Haszler, and A. Vieregge: Mater Sci. Eng., 2000, vol. 280A, pp. 37-49.

3. S.A. Court, K.M. Gatenby, and D.J. Lloyd: Mater. Sci. Eng., 2001, vols. 319A-321A, pp. 443-47.

4. J. Sarkar, T.R.J. Kutty, D.S. Wilkinson, J.D. Embury, and J.D. Lloyd: Mater. Sci. Eng., 2001, vol. 316, pp. 52-59.

5. F. Ozturk, S. Toros, and H. Pekel: Mater. Sci. Technol., 2009, vol. 25, pp. 919-24.

6. S.A. Court, K.M. Gatenby, and D.J. Lloyd: Mater. Sci. Eng., 2001, vols. 319A-321A, pp. 443-47.
7. D.J. Lloyd and S.A. Court: Mater. Sci. Technol., 2003, vol. 19, pp. $1349-54$.

8. T. Komatsubara, T. Muramatsu, and M. Matsuo: European Patent No. 0259700B1, 1990.

9. T. Fujita, K. Hasegawa, and M. Suga: European Patent No. 0616044A2, 1994.

10. O. Umezawa, M. Nakamoto, Y. Osawa, K. Suzuki, and S. Kumai: Mater. Trans., 2005, vol. 46, pp. 2609-15.

11. L.F. Mondolfo: Al Alloys: Structure and Properties, Butterworths, London, 1976.

12. L. Backerud, E. Krol, and J. Tamminen: Solidification Characteristics of Al Alloys, Wrought Alloys, Skanaluminium, Oslo, Norway, 1986, vol. 1, pp. 113-23.

13. S. Martinez De La Puente, B. Verlinden, and Delaey: J. Mater. Sci., 1994, vol. 29, pp. 6167-74.

14. F.H. Samuel, A.M. Samuel, H.W. Doty, and S. Valtierra: Metall. Mater. Trans. A, 2003, vol. 34A, pp. 115-29.

15. Y.J. Li and L. Arnberg: Acta Mater., 2004, vol. 52, pp. 2673-81.

16. C.A. Ahravci and M.O. Pekguleryuz: CALPHAD, 1998, vol. 22, pp. $147-55$.

17. C.M. Allen, K.A.Q. O'Reilly, B. Cantor, and P.V. Evans: Progr. Mater. Sci., 1998, vol. 43, pp. 89-70.

18. K. Spencer, S.F. Corbin, and D.J. Lloyd: Mater. Sci. Eng., 2002, vol. 325A, pp. 394-04.

19. X. Fang, G. Shao, Y.Q. Liu, and Z. Fan: Mater. Sci. Eng., 2007, vols. 445-446A, pp. 65-72.

20. G. Liu, Y. Wang, and Z. Fan: Mater. Sci. Eng., 2008, vol. 472A, pp. 251-57.

21. R. Haghayeghi, Y. Liu, and Z. Fan: Solid State Phen., 2008, vols. 141-143, pp. 403-08.

22. Z. Fan, M. Xia, H. Shang, G. Liu, J.B. Patel, Z. Bian, I. Bayandorian, Y. Wang, H.T. Li, and G.M. Scamans: Int. J. Cast Met. Res., 2009, vol. 22, pp. 103-07.

23. Z. Fan, Y. Wang, Z.F. Zhang, M. Xia, H.T. Li, J. Xu, L. Granasy, and G.M. Scamans: Int. J. Cast Met. Res., 2009, vol. 22, pp. 31822.

24. Z. Fan, Y. Wang, M. Xia, and S. Arumuganathar: Acta Mater., 2009, vol. 27, pp. 4891-4901.

25. Y. Zuo, H. Li, M. Xia, B. Jiang, G.M. Scamans, and Z. Fan: Scripta Mater., 2011, vol. 64, pp. 209-12.

26. Z. Fan, M.J. Bevis, and S. Ji: PCT patent WO 01/21343 A1, 1999.

27. Z. Fan, S. Ji, and M.J. Bevis: PCT patent WO 02/13993 A1, 2000.

28. H. Hlim, D.S. Wilkinson, and M. Niewczas: Acta Mater., 2007, vol. 55, pp. 4151-60.

29. B. Dutta and M. Rettenmayr: Mater. Sci. Eng., 2000, vol. 283, pp. 218-24.

30. Z. Chen and M.J. Worswick: Mater. Sci. Eng., 2008, vols. 483484, pp. 99-01.

31. C.I.A. Thomson, M.J. Worswick, A.K. Pilkey, and D.J. Lloyd: J. Mech. Phys. Solids, 2003, vol. 51, pp. 127-46.

32. G. Scamans and Z. Fan: Aluminum, 2009, vol. 21, pp. 19-21.

33. D. Liang and H. Jones: Z. Metallkd., 1992, vol. 83, pp. 224-26.

34. X. Cao and J. Campbell: Metall. Mater. Trans. A, 2003, vol. 34A, pp. $1409-19$

35. X. Cao and J. Campbell: Metall. Mater. Trans. A, 2004, vol. 35A, pp. 1425-35.

36. W. Khalifa, F.H. Samuel, J.E. Gruzleski, H.W. Doty, and S. Valtierra: Metall. Mater. Trans. A, 2005, vol. 36A, pp. 1017-32. 